

\title{
Evaluation of Antibacterial Effect of Different Sucrose Free Hard Candies in High-Risk Patients
}

\author{
Doha M. Gad ${ }^{1 *}$,Maha A. Niazy ${ }^{2}$, Hadeel F. Mohamed ${ }^{3}$
}

Codex : 07/21.10

azhardentj@azhar.edu.eg

http://adjg.journals.ekb.eg

DOI: $10.21608 /$ adjg.2021.48691.1320

Restorative Dentistry

(Removable Prosthodontics, Fixed

Prosthodontics, Endodontics, Dental Biomaterials, Operative Dentistry)

\section{KEYWORDS}

Hard candies,

Mutans streptococci,

Salivary $\mathrm{pH}$, Licorice, Xylitol

\begin{abstract}
Purpose: This study was conducted to evaluate the effect of four different hard candies on salivary Streptococcus mutans count and change in salivary $\mathrm{pH}$ in a group of Egyptian college students. Materials and Methods: Forty-eight healthy dental students, aged 16 -22 years were randomly allocated into 4 different study groups each of 12 students: sucrose free hard candies with licorice extract group, sucrose free hard candies with xylitol extract group, sucrose free hard candies group, and sucrose containing hard candies group (control). Unstimulated saliva was collected from the participants at baseline, following which the participants were given respective hard candies twice daily for 10 days and the subsequent salivary samples were collected at intervals of 14 days and 6 months. The samples were analyzed for Streptococcus mutans count in terms of CFU and $\mathrm{pH}$ using $\mathrm{pH}$ meter. Results: Regarding baseline 14 days interval, there was a statistically significant decrease in mean percentage change on bacterial count in licorice and xylitol group Moreover there was also a significant difference in salivary $\mathrm{pH}$ between different hard candies Conclusion: Addition of licorice or xylitol to sucrose free hard candies enhances its effect on streptococcus mutans and can shift salivary $\mathrm{pH}$ to a neutral value.
\end{abstract}

\section{INTRODUCTION}

With the progressive development in dental field, dental caries is still a problem all over the world. In spite of being a multifactorial disease, no one can deny the important role of bacteria as the main etiologic

- Paper extracted from Doctor thesis titled "Evaluation of Anticariogenic Potential of Different Sugar Free Flavoured Hard Candies"

1. Assistant Lecturer at Conservative Dentistry Department, Faculty of Oral and Dental Medicine, Ahram Canadian University, Cairo, Egypt.

2. Professor of Operative Dentistry Department, Faculty of Dental Medicine for Girls, Al-Azhar University, Cairo, Egypt.

3. Associate Professor at Conservative Dentistry Department, Faculty of Oral and Dental Medicine, Ahram Canadian University, Cairo, Egypt.

* Corresponding author email: dohamostafa1@hotmail.com 
factor ${ }^{(1)}$.Without cariogenic bacteria, dental caries will not develop or progress. The oral cavity is a shelter for 500- 1000 types of bacteria, fungi, protozoa and viruses. Total eradication of bacteria is almost unachievable, but, a decrease in the total bacterial count can hinder the cariogenic process ${ }^{(2)}$.

Intake of sugar such as sucrose is one of the critical factors in development of caries. Sucrose is considered the highest cariogenic factor in the process of caries progression. Sucrose is metabolized by oral bacteria and also enhances the growth and colonization of Streptococus mutans. Additionally, sucrose acts as a substrate for extracellular polysaccharides production in dental biofilms ${ }^{(3)}$. Extracellular polysaccharides improve the stability of biofilm matrixes and physical integrity of biofilm matrixes, which indicate that EPSs is a virulent factor related to cariogenic biofilm formation and acid production by cariogenic bacteria which dissolve tooth structure ${ }^{(4)}$.

Depending on the chemistry of demineralization and remineralization raising the $\mathrm{pH}$ of the oral cavity can combat acids produced by cariogenic bacteria and hence promote remineralization process. During demineralization, minerals diffuse out of the tooth by passive diffusion. Unless the $\mathrm{pH}$ of the oral cavity is neutralized to stop the demineralization process and outward diffusion of minerals, remineralization will not occur ${ }^{(5)}$.

Owing to the fact that caries is an infectious disease, antimicrobial interventions against cavity causing bacteria can prevent tooth decay. Certainly, studies have shown that antimicrobial agents can be administered to the oral cavity and reduce tooth decay. Many sucrose-free products have been claimed to prevent caries and provide oral health benefits ${ }^{(6)}$. It also can reduce the count of Streptococcus mutans which is one of the wellknown cavity causing bacteria in the oral cavity ${ }^{(7)}$.

Glycyrrhiza glabra (licorice) is a herbal product with a medicinal effect. The Egyptians, Greeks and Romans have utilized this medicine to treat different types of illness. Many studies reported that the compounds isolated from licorice possess antitumor, antiviral, anti-inflammatory and antimicrobial effect specially against streptococcus mutans. It can inhibit the glycosyltransferase activity of Streptococcus mutans, reduce plaque formation, and show antibacterial effect against $\mathrm{S}$. mutans, Streptococcus sobrinus, Porphyromonas gingivalis, and Prevotella intermedia ${ }^{(8)}$.

Xylitol is a sugar substitute and a natural sweetener in many products. The use of xylitolcontaining products can be effective in preventing caries. It increases the flow of saliva, raise oral $\mathrm{pH}$ and aid in the remineralization of enamel. In addition, xylitol also can reduce plaque growth and by reducing the concentration (CFU) of cariogenic bacteria species in the dental plaque (CFU) and in saliva $^{(9)}$.

Stevia rebaudiana is an herbaceous perennial plant of the family Asteraceae, and its extract can be used to sweeten foods and it is also a dietary supplement. The major components are glycosides, namely, stevioside and rebaudioside-A. It has been suggested that it have an antihypertensive, antihyperglycemic, and an antioxidant. Many studies have compared the antibacterial potential of S. rebaudiana. However, only few studies have been reported on its effect on Streptococcus mutans of the oral cavity $^{(10)}$.

Realizing the fact that habitual use of sucrose containing hard candies can have a flourishing effect on cariogenic bacteria so by shifting this habit to a more beneficial product it could target against streptococcus mutans without any side effect. Therefore, this study aimed to compare the antibacterial potential of licorice and xylitol containing sucrose free hard candies in high caries risk patients. 


\section{MATERIAL AND METHODS}

\section{Subject selection:}

This randomized clinical trial was approved by the Ethical Committee of Faculty of Dental Medicine for Girls Al Azhar University (registration No.REC18-056).

A total number of 48 college students were selected from Faculty of Oral and Dental medicine, Ahram Canadian University. Inclusion criteria were systemically free college students of ages ranging from (16-22) years. Those students are high caries risk candidates defined according to CAMBRA (caries management by risk assessment) and they take candies as a daily sugary snack while following a moderate oral hygiene measures by brushing their teeth twice daily with a fluoridated tooth paste. They also must have at least two posterior teeth with initial proximal lesions E1 or E2 according to radiographic classification of dental caries. While exclusion criteria included subjects, who wore orthodontic appliances or removable prosthesis, subjects suffering from any medical or systematic disease and those who have allergy to any of the hard candies' ingredients.

\section{Grouping:}

Subjects were randomly distributed into four groups each of 12 subjects. Group 1 was subjects who took hard candies with licorice extract sweetened with stevia, Group 2 subjects who took hard candies with xylitol extract sweetened with stevia, Group 3 subject who took hard candies sweetened with stevia and Group 4 subjects who took hard candies sweetened with sucrose. Each subject was instructed to take 2 candies daily for 10 days ${ }^{(11)}$, Saliva sampling from each subject was carried out before intervention $\left(\mathrm{T}_{0}\right.$, after 14 days from baseline saliva $\left(\mathrm{T}_{1)}\right.$ and 6 months after intervention $\left(\mathrm{T}_{2}\right)$.

\section{Collection of saliva sample:}

Unstimulated saliva samples were collected from each subject by asking him/her to spit in a sterile plastic container till a suitable amount collected $(5 \mathrm{ml})$, It was done in the morning from 9 to $10 \mathrm{am}$. The subject was asked to refrain from eating, drinking or any oral hygiene measures for at least one hour prior to saliva collection. Baseline sample $\left(\mathrm{T}_{0}\right)$ was taken before having the hard candies. Second sample $\left(T_{1}\right)$ was taken 14 days from the baseline sample. Third sample $\left(\mathrm{T}_{2}\right)$ was taken 6 months from the baseline sample.

\section{Isolation and identification of Streptococcus mutans:}

Freshly collected saliva samples were diluted based on a pilot study done before to determine the dilution factor which can produce countable plates and $100 \mu \mathrm{L}$ of the diluted samples were uniformly spread on Mitis Salivaris Agar with Bacitracin agar plate's (MSBA) surface. The plates were sealed and incubated anaerobically and supplied in an anaerobic jar, for 24 hours at $37^{\circ} \mathrm{C}$. Colonies of Streptococcus mutans were identified based on its unique morphology on MSBA. Raised, convex, opaque colonies of dark blue color with rough margins and granular frosted glass appearance were identified as S. mutans (Fig. 1). Under microscopic examination. S. mutans appeared as Gram positive cocci arranged in chains.

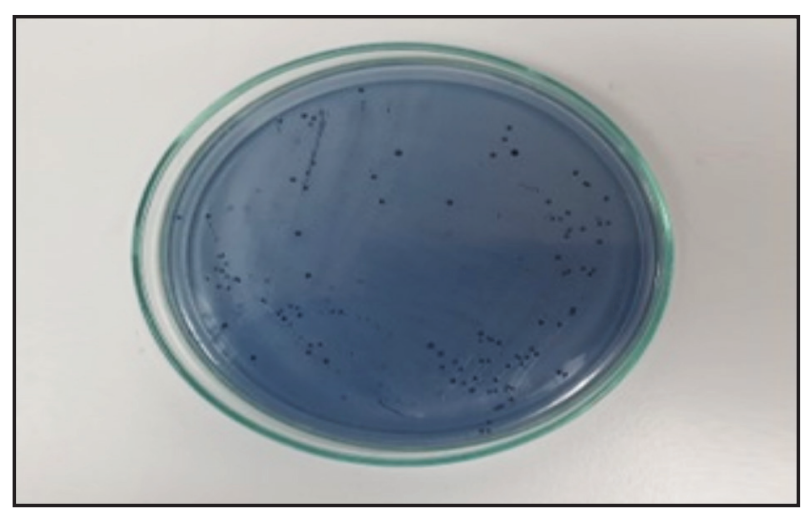

Figure (1) Streptococcus Mutans growth on MSB agar. 


\section{Salivary pH measurements:}

The $\mathrm{pH}$ of the unstimulated saliva was recorded using a $\mathrm{pH}$ meter (Adwa AD-11) (Adwa Hungary Kft.Alsó-Kikötö sor 11.C6726 Szeged). The pH meter was calibrated before measuring the saliva by inserting the electrode in buffer solutions accompanied with the device which are of $\mathrm{pH} 4$ (acetic acid) and 7 (phosphate buffered saline). Then, the electrode was inserted directly into the collected saliva and the $\mathrm{pH}$ was recorded. After each measurement, the electrode was rinsed with water to keep it clean.

\section{Statistical analysis}

Statistical analysis was performed using IBM SPSS Statistics Version 2.0 for Windows. Data was presented as mean, standard deviation (SD) and percentage change. Kolmogorov-Smirnov and Shapiro-Wilk tests were used to assess data normality. The significance level was set at $\mathrm{P} \leq 0.05$. KruskalWallis test followed by Mann-Whitney test were conducted to compare salivary $\mathrm{pH}$ and percentage change in bacterial count between different sugarfree candies at each evaluation time. Friedman test followed by Wilcoxon signed-rank test was used for comparisons of salivary $\mathrm{pH}$ and percentage change in bacterial count between different evaluation times within each candy group.

\section{RESULTS}

A total of 40 subjects completed the experimental period. Causes of dropout were mainly subjects who refused to complete to experiment or subject who didn't comply to the experiment rules. Data on streptococcus mutans count in terms of CFU and salivary $\mathrm{pH}$ refer to 10 subjects in each group.

Results of changes in streptococcus mutans count in terms of (CFU) using Kruskal-Wallis test followed by Mann-Whitney showed that there was a statistically significant difference in mean percentage change in colony forming unit of Streptococcus mutans (\%) in between different hard candies within each time interval (baseline - 14 days at $\mathrm{P}<0.001,14$ days -6 months at $\mathrm{P}<0.003$ and baseline -6 months at $\mathrm{P}<0.001)$.

Regarding baseline - 14 days interval, Group 1 and Group 2 yielded significantly higher mean percentage change compared to Group 3 and Group 4. As for 14 days -6 months interval, candies with group 2 showed the significantly highest mean percentage change, followed by Group 1 and Group 3. (Table 1 and Fig. 2) while Group 4 displayed the significantly least percentage change. Whereas for baseline - 6 months interval, Group 3 yielded the significantly least percentage change compared to the other 3 groups which were statistically similar.

Table (1) Mean percentage change and P-value for the effect of hard candies on streptococcus mutans count in terms of $(\mathrm{CFU})$ at different time intervals.

\begin{tabular}{lccc}
\hline & $\begin{array}{c}\text { Baseline - } \\
\text { 14 days }\end{array}$ & $\begin{array}{c}\text { 14 days - } \\
\text { 6 months }\end{array}$ & $\begin{array}{c}\text { Baseline - } \\
\text { 6 months }\end{array}$ \\
\hline Group 1 & $43.21 \%^{\mathrm{a}}$ & $-26.29 \%^{\mathrm{b}}$ & $28.28 \%^{\mathrm{a}}$ \\
\hline Group 2 & $51.67 \%^{\mathrm{a}}$ & $-51.04 \%^{\mathrm{a}}$ & $27.01 \%^{\mathrm{a}}$ \\
\hline Group 3 & $18.88 \%^{\mathrm{b}}$ & $-17.87 \%^{\mathrm{b}}$ & $4.39 \%^{\mathrm{b}}$ \\
\hline Group 4 & $-16.16 \%^{\mathrm{b}}$ & $-4.20 \%^{\mathrm{c}}$ & $-21.04 \%^{\mathrm{a}}$ \\
\hline P-value & $<0.001^{*}$ & $<0.003^{*}$ & $<0.001^{*}$ \\
\hline
\end{tabular}

*: significant at $P \leq 0.05$

Means with different superscript lowercase letters within each column are statistically significantly different at $P \leq 0.05$

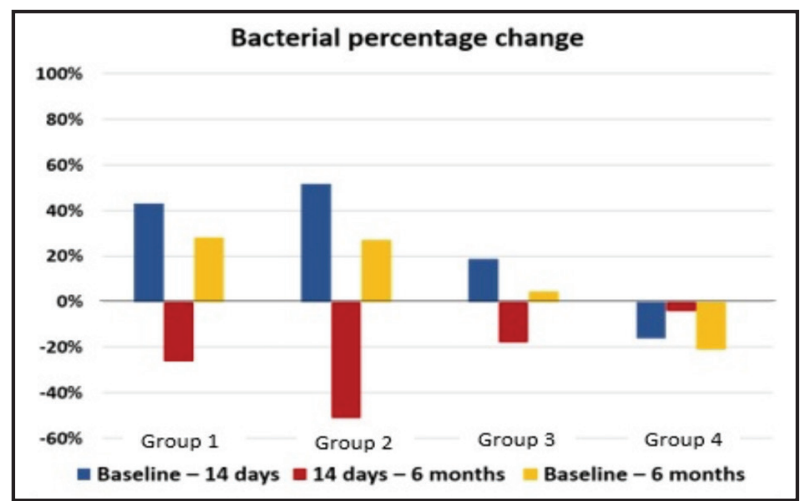

Figure (2) Bar chart showing bacterial percentage change at each time interval after consumption of different hard candies. 
Results of changes in salivary $\mathrm{pH}$ using Friedman test followed by Wilcoxon signed-rank test showed that there was a statistically significant difference in mean salivary $\mathrm{pH}$ between different evaluation times within Group $1(\mathrm{P}<0.001)$ and Group 2 $(\mathrm{P}<0.001)$. In both groups, salivary $\mathrm{pH}$ recorded at baseline was significantly lower than that recorded after 14 days and 6 months; which yielded no statistically significant difference. While, there was no statistically significant difference in salivary $\mathrm{pH}$ between different evaluation times within Group 3 group $(\mathrm{P}=0.105)$ and Group $4(\mathrm{P}=0.275)$. (Table 2 and Fig. 3)

Table (2) Means and P-value for the effect of evaluation time on salivary $\mathrm{pH}$ within each hard candy group.

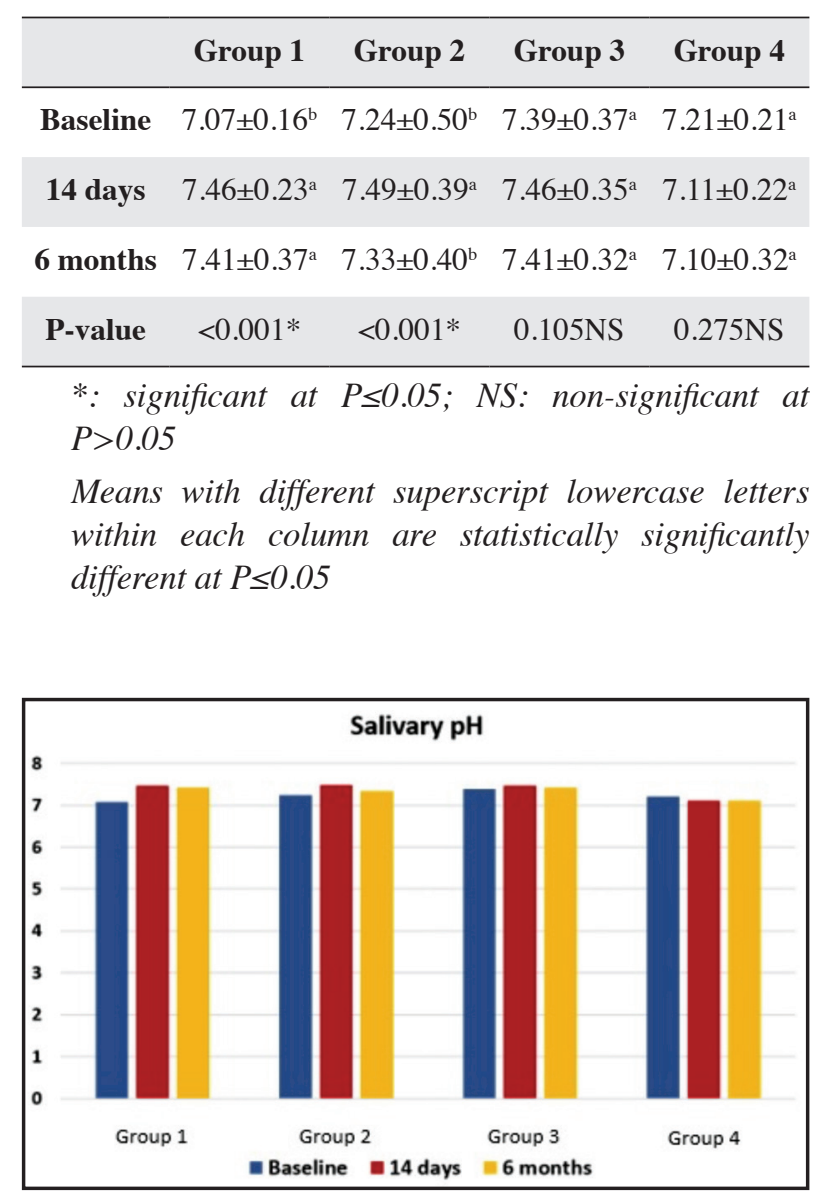

Figure (3) Bar chart showing salivary $\mathrm{pH}$ within each hard candy group at different evaluation times.
Pearson's correlation coefficient (Table 3) showed that there was no correlation between bacterial count and salivary $\mathrm{pH}(\mathrm{r}=-0.050, \mathrm{P}=0.551)$.

Table (3) Pearson's correlation coefficient ( $r$ ) and $P$-value for the correlation between bacterial count and salivary $\mathrm{pH}$.

\begin{tabular}{ccc}
\hline Variables & $\begin{array}{c}\text { Pearson Correlation } \\
(\mathbf{r})\end{array}$ & P-value \\
\hline $\begin{array}{c}\text { Bacterial count } \mathbf{x} \\
\text { Salivary } \mathbf{p H}\end{array}$ & -0.050 & $0.551 \mathrm{NS}$ \\
\hline
\end{tabular}

NS: not significant at $>0.05$

\section{DISCUSSION}

Dental caries is one of the major public health problems and it affects approximately $90 \%$ of the children and $60 \%$ adults across the globe. Incidence of dental caries among population led to the appearance of many preventive protocols that saves time and efforts ${ }^{(12)}$. Sucrose free hard candies is an appealing method to have a treat without having the harmful effect of consuming sugar. So, this study was conducted to evaluate the effect of hard candies containing licorice extract and sweetened with stevia, hard candies xylitol extract and hard candies sweetened with stevia on the salivary streptococcus mutans count, changes in the salivary $\mathrm{pH}$.

In this study, inclusion criteria included patients with high caries risk and at least two initial enamel lesions as those are the targeted population who are at increased risk for caries development and need an intervention to have an anticariogenic effect ${ }^{(11)}$. Also, age group was standardized between 1620 years old college students as studies showed that most college students consumed one sugarsweetened snack daily or at least several times per week. Moreover, most students rarely/never chose a product based on the type of sweetener used but rather rely on its taste and cost ${ }^{(13)}$. While in the exclusion criteria, smokers and any participants under medications were excluded as it might have affected saliva flow and composition. Using these 
parameters, 48 patients were selected for this study according to sample size calculations.

Salivary microbial count and $\mathrm{pH}$ are biological indicators for high caries risk patients ${ }^{(14)}$. Streptococcus mutans metabolizes the easy fermentable sugars to produce lactic acid that results in the acidic $\mathrm{pH}$ of the saliva/biofilm and this helps in growth of aciduric and acidogenic organisms and results in demineralization of the tooth structure. As saliva plays a major role in regulating remineralization/ demineralization process, care should be given to help in reducing the count of S. mutans and keeping $\mathrm{pH}$ shifted toward neutral value ${ }^{(15)}$.

Results showed that hard candies with licorice extract and candies with xylitol extract yielded a higher mean percentage of change in streptococcus mutans count in terms of CFU in (baseline - 14 days) interval and this may be attributed to the presence of alkaloids, tannins and essential oils in licorice root which prevent the adherence of bacteria to the tooth surfaces, inhibit the production of glucan and have inhibitory action on amylases. This is in accordance with the many studies (16,17) which also stated that glabridine one of the most important constituents of licorice root has a direct effect against both gram-positive strains and gram-negative strains. Moreover, the presence of glycyrrhizin, glycyrrhetinic acid, asparagine and chalcones in the licorice root extract improves its antiadhesive and antimicrobial properties. Added to that flavonoids namely 1 methoxyficifolinol, licorisoflavan A and 6,8-diprenylgenistein isolated from licorice root extract have shown to completely inhibit the formation of biofilm hence recommended for prevention of dental caries ${ }^{(18)}$.

While the anticariogenic effect of hard candies with xylitol extract might be related to the phosphorylation and transport of the xylitol through the cell wall of streptococcus mutans by a constitutive fructose-PTS (phosphotransferase) system with accumulation of xylitol-5-phosphate in intracellular substrate which lead to inhibition of growth of streptococcus mutans ${ }^{(19,20)}$.Xylitol also reduces dental plaque formation and bacterial adherence (i.e., it is antimicrobial), inhibits demineralization of enamel (i.e. reduces acid production) and has a direct inhibitory effect on Streptococcus mutans. The continuous-culture biofilm model showed that, sucrose increases the bacterial colonization and proliferation significantly whereas xylitol reduces it. The results indicate that xylitol affects the adherence of S. mutans to the hydroxyapatite ${ }^{(21,22)}$.

As for 14 days - 6 months interval, hard candies with xylitol extract showed significantly highest mean percentage change, this increase in streptococcus mutans count this can be partly explained by the fact that long-term xylitol consumption modifies the distribution of S. mutans between the saliva and dental plaque, leading to the appearence of xylitol resistant streptococcus mutans in humans .It was suggested that xylitol resistant streptococcus mutans may be less virulent and less cariogenic than xylitol sensitive streptococcus mutans . On the other hand, there are studies that reported that there is no difference in the amount of acid and polysaccharide production by xylitol sensitive streptococcus mutans and xylitol resistant streptococcus mutans ${ }^{(23)}$.

In 14 days -6 months interval hard candies with sucrose group displayed the significantly least percentage change despite the fact that sucrose is the most cariogenic carbon source and that cariogenic bacteria showed the highest cell division rate and the strongest acid synthesis with the addition of sucrose $^{(24)}$, this may be attributed to subjects following moderate oral hygiene measures where they brushed their teeth twice daily with a fluoridated tooth paste this might have limited the cariogenic effect of hard candies sweetened with sucrose ${ }^{(25)}$.

Whereas for baseline - 6 months interval, sucrose free candies sweetened with stevia yielded the significantly least percentage change this might be explained by the fact that stevia didn't act as 
bactericidal agent against cariogenic bacteria, but it did not promote streptococcus mutans cell proliferation as sucrose. Furthermore, stevia, showed a general trend to decrease the production of polysaccharides ${ }^{(26)}$.

Interesting findings were revealed for the relationship between MS and plaque $\mathrm{pH}$. It was found that the salivary $\mathrm{pH}$ of subjects who took hard candies with licorice extract for 10 days increased significantly form baseline measurement. In an acid production test, licorice extract was shown to reduce production of acids. Licorice is an alkaline food and was proven to have a protective effect in peptic ulcer and gastro esophageal reflux disease. Moreover, the organoleptic properties of licorice can stimulate salivary flow and since stimulated saliva contains a great concentration of bicarbonate ions it will increase the buffering capacity ${ }^{(27)}$.

Similarly xylitol has the ability to increase the flow of saliva in the oral cavity, without increasing the concentration of acids in the dental plaque, controlling the $\mathrm{pH}$ and the buffering capacity of saliva after the consumption of sucrose ${ }^{(28)}$.Moreover xylitol is a non-fermentable sugar from bacteria of the genus Streptococcus, mainly S. mutans, in addition it also acts in the process of remineralization, preventing the $\mathrm{pH}$ drop in the oral cavity due to its inhibitory power of growth of cariogenic bacteria. In this context, the use of xylitol for oral washing increases the salivary flow and consequently increases the $\mathrm{pH}$ of the saliva, neutralizing acids that are produced by fermentable sugars ${ }^{(29)}$.

\section{CONCLUSION}

Sucrose free hard candies with licorice or xylitol extract showed antibacterial properties, though its effect vanishes after short period of time. Despite the effect of sucrose-free hard candies on reduction of cariogenic bacteria, their effect on $\mathrm{pH}$ was nearly shifted to the neutral value.

\section{REFERENCES}

1. Korkmaz F, Özel M, Tuzuner T, Korkmaz B, Yayli N. Antimicrobial activity and volatile constituent analysis of three commercial herbal toothpastes containing aloe veral. and fragaria vesca 1. extracts. Niger J Clin Pract. 2019;22:718-26.

2. Mohamed E, El- Sayed S, Zaghloul S. Antibacterial efficacy of aloe vera extract mouth wash versus chlorhexidine in pediatrics: An in vivo study. Al-Azhar D J. 2020; $7: 475-81$.

3. Abdel Tawab H, Niazy M, Elsharkawy D. Antibacterial effect of ginger, green tea and pomegranate versus chlorhexidine using stevia and sucrose sugar. Al-Azhar D J. 2020; 7:329-36.

4. Dang MH, Jung JE, Choi HM, Jeon JG. Difference in virulence and composition of a cariogenic biofilm according to substratum direction. Sci Rep. 2018; 8:6244-52.

5. Liang K, Zhou H. Poly (amido amine) and calcium phosphate nanocomposite remineralization of dentin in acidic solution without calcium phosphate ions. Dent Mater. 2017; 33: 818-29.

6. Mosallama R, Shabaan M. Effect of sugared chewing gum versus sugar free chewing gum after acidic challenge on caries profile of young adults using cariogram. A randomized control trial. Egypt Dent J. 2019; 65:1671-8.

7. Tanushri MD P. Effect of Mouth Rinsing with Solutions Containing Different Commercially Available Sugar Substitutes on Salivary pH- An In Vivo Randomized Controlled Trial. Indian J. Med. Res. 2017; 4:6-14.

8. Malvania EA, Sharma AS, Sheth SA, Rathod S, Chovatia NR, Kachwala MS, et al. In vitro analysis of licorice (Glycyrrhiza glabra) root extract activity on streptococcus mutans in comparison to chlorhexidine and fluoride mouthwash. Contemp Clin Dent. 2019; 20:1389-94.

9. Escobar E, Piedrahita M, Gregory RL. Growth and viability of Streptococcus mutans in sucrose with different concentrations of Stevia rebaudiana bertoni. Clin Oral Investig. 2020; 24:3237-42.

10. Shinde MR, Winnier J. Health benefits and application of Stevia rebaudiana bertoni in dentistry. J. Drug Deliv. Ther. $2020 ; 10: 271-4$.

11. Almaz ME, Sönmez IŞ, Ökte Z, Oba AA. Efficacy of a sugar-free herbal lollipop for reducing salivary Streptococcus mutans levels: A randomized controlled trial. Clin Oral Investig. 2017; 21:839-45.

12. Dhanker K, Chaudhary A, Sharma S, Kaur N. Fluoride alternatives in the prevention of dental caries: A Review. Int. Healthcare J. 2019; 2:298-303. 
13. Khawaja AH, Qassim S, Hassan NA, Arafa ES. Added sugar: Nutritional knowledge and consumption pattern of a principal driver of obesity and diabetes among undergraduates in UAE. Diabetes \& Metabolic Syndrome. Clin Res \& Rev. 2019; 13:2579-84.

14. Campus G, Cagetti MG, Sacco G, Solinas G, Mastroberardino S, Lingström P, et al. Six months of daily high-dose xylitol in high-risk schoolchildren: A randomized clinical trial on plaque $\mathrm{pH}$ and salivary mutans streptococci. Caries Res. 2009; 43:455-61.

15. Usha C, Ramarao S, John BM, Babu ME. Anticariogenicity of Stevia rebaudiana extract when used as a mouthwash in high caries risk patients: Randomized controlled clinical trial. World J. Dent. 2017; 8:364-9.

16. Messier C, Epifano F, Genovese S, Grenier D. Licorice and its potential beneficial effects in common oro-dental diseases. J. Oral Dis. 2012; 18:32-9.

17. Hambire C, Hambire U. Glycyrrhiza glabra: Its role in dentistry. J Res Dent Sci. 2020; 11:106-9.

18. Sidhu P, Shankargouda S, Rath A, Hesarghatta RP, Fernandes B, Kumar SA, et al. Therapeutic benefits of liquorice in dentistry. J Ayurveda Integr Med. 2020; 11:82-8.

19. Kõljalg S, Smidt I, Chakrabarti A, Bosscher D, Mändar R Exploration of singular and synergistic effect of xylitol and erythritol on causative agents of dental caries. Sci. Rep. $2020 ; 10: 1-7$

20. Cocco F, Cagetti MG, Majdub O, Campus G. Concentration in saliva and antibacterial effect of Xylitol chewing gum: In vivo and in vitro study. J Appl Sci. 2020; 10:8-17.

21. Gupta M. Sugar substitutes: Mechanism, availability, current use and safety concerns-an update. J. Med. Sci.2018; 6:1888-94.
22. Salli KM, Forssten SD, Lahtinen SJ, Ouwehand AC. Influence of sucrose and xylitol on an early Streptococcus mutans biofilm in a dental simulator. Arch. Oral Biol. 2016; 70:39-46.

23. Lee SH, Choi BK, Kim YJ. The cariogenic characters of xylitol-resistant and xylitol-sensitive Streptococcus mutans in biofilm formation with salivary bacteria. Arch. Oral Biol 2012; 57:697-703.

24. Ganter J, Hellwig E, Doerken S, Al-Ahmad A. In vitro evaluation of the cariogenic potential of rebaudioside A compared to sucrose and xylitol. Clin Oral Investig. 2020; 24:113-22.

25. Prabakar J, John J, Arumugham IM, Kumar RP, Sakthi DS . Comparing the effectiveness of probiotic, green tea, and chlorhexidine- and fluoride-containing dentifrices on oral microbial flora: A double-blind, randomized clinical trial. Contemp Clin Dent. 2018; 9:560-67.

26. Giacaman RA, Campos P, Muñoz-Sandoval C, Castro RJ. Cariogenic potential of commercial sweeteners in an experimental biofilm caries model on enamel. Arch. Oral Biol. 2019; 58:1116-22.

27. Söderling E, Karjalainen S, Lille M, Maukonen J, Saarela M, Autio K, et al. The effect of liquorice extract-containing starch gel on the amount and microbial composition of plaque. Clin Oral Investig. 2006; 10:108-13.

28. Escalante-Medina RP, Asmat-Abanto S, Ruiz-Barrueto MA. Effect of a commercial toothpaste containing xylitol on the count of streptococcus mutans in saliva of pregnant women: Randomized Controlled Clinical Trial. Int. J Odontostomat. 2019; 13:316-20.

29. Siqueira Fraga EG, Teófilo Campos FM, Silva Cavalcante MP, Barbosa Martins LF, Rodrigues Neto EM, Mimica MJ, et al. Xylitol, a promising allied for oral health. J. Young Pharm. 2020; 12:197-200. 